\title{
Increasing upper limb training intensity in chronic stroke using embodied virtual reality: a pilot study
}

Daniel Perez-Marcos ${ }^{1 *} \mathbb{D}$, Odile Chevalley ${ }^{1,2}$, Thomas Schmidlin ${ }^{3}$, Gangadhar Garipelli ${ }^{1} \mathbb{D}$, Andrea Serino ${ }^{1,3,4}(\mathbb{D}$, Philippe Vuadens ${ }^{5}$, Tej Tadi ${ }^{1}$, Olaf Blanke ${ }^{2,3+}$ and José d. R. Millán ${ }^{3,6+}$ (D)

\begin{abstract}
Background: Technology-mediated neurorehabilitation is suggested to enhance training intensity and therefore functional gains. Here, we used a novel virtual reality (VR) system for task-specific upper extremity training after stroke. The system offers interactive exercises integrating motor priming techniques and embodied visuomotor feedback. In this pilot study, we examined (i) rehabilitation dose and training intensity, (ii) functional improvements, and (iii) safety and tolerance when exposed to intensive VR rehabilitation.
\end{abstract}

Methods: Ten outpatient stroke survivors with chronic ( $>6$ months) upper extremity paresis participated in a tensession VR-based upper limb rehabilitation program (2 sessions/week).

Results: All participants completed all sessions of the treatment. In total, they received a median of 403 min of upper limb therapy, with 290 min of effective training. Within that time, participants performed a median of 4713 goal-directed movements. Importantly, training intensity increased progressively across sessions from 13.2 to 17.3 movements per minute. Clinical measures show that despite being in the chronic phase, where recovery potential is thought to be limited, participants showed a median improvement rate of 5.3\% in motor function (Fugl-Meyer Assessment for Upper Extremity; FMA-UE) post intervention compared to baseline, and of 15.4\% at one-month follow-up. For three of them, this improvement was clinically significant. A significant improvement in shoulder active range of motion (AROM) was also observed at follow-up. Participants reported very low levels of pain, stress and fatigue following each session of training, indicating that the intensive VR intervention was well tolerated. No severe adverse events were reported. All participants expressed their interest in continuing the intervention at the hospital or even at home, suggesting high levels of adherence and motivation for the provided intervention.

Conclusions: This pilot study showed how a dedicated VR system could deliver high rehabilitation doses and, importantly, intensive training in chronic stroke survivors. FMA-UE and AROM results suggest that task-specific VR training may be beneficial for further functional recovery both in the chronic stage of stroke. Longitudinal studies with higher doses and sample sizes are required to confirm the therapy effectiveness.

Trial registration: This trial was retrospectively registered at ClinicalTrials.gov database (registration number NCT03094650) on 14 March 2017.

Keywords: Stroke, Neurorehabilitation, Virtual reality, Rehabilitation dose, Motor rehabilitation, Training intensity, Embodied feedback

\footnotetext{
*Correspondence: daniel.perez@mindmaze.ch

${ }^{\dagger}$ Equal contributors

'MindMaze SA, Lausanne, Switzerland

Full list of author information is available at the end of the article
} 


\section{Background}

Stroke affects about 17 million people per year worldwide, with an increasing rate every year [1]. Stroke survivors often suffer from physical and mental disabilities, heavily impacting their quality of life. Five years after the first stroke, nearly $66 \%$ of patients exhibit different degrees of disability and only $34 \%$ are functionally independent in their activities of daily living [2].

\section{Motor rehabilitation after stroke}

Motor dysfunction is the most prevalent impairment, with 9 out of 10 stroke survivors suffering from some form of upper limb motor disability [3], and it is a strong predictor of poor functional recovery [4]. Thus, there is a strong need for rehabilitative approaches enhancing motor recovery for stroke patients [5]. To maximize neural, motor and functional recovery, training needs to be longlasting, challenging, repetitive, task-specific, motivating, salient, and intensive [6]. Standard motor rehabilitation after stroke typically includes neurofacilitation techniques, task-specific training and task-oriented training [7]. Further approaches include strength training, trunk restraint, somatosensory training, constraint-induced movement therapy, bilateral arm training, coordination of reach to grasp, mirror training, action observation and neuromuscular electrical stimulation [8].

Time scheduled for therapy and its frequency are determinant factors for the outcome of motor rehabilitation [9], with a recommended initial amount of at least 45 min for a minimum of 5 days per week [10]. However, the frequency of the delivered therapy usually decreases with time, with therapy being discontinued between 3 and 6 months after the vascular accident [7]. Under these rehabilitation conditions, recovery of motor function has been observed to be strongest during the first month after stroke and to slow down during subsequent months, reaching a "plateau" by 3-6 months post stroke $[11,12]$. Clinical evidence for motor improvement in chronic stroke [13] suggests that the "plateau" may depend not only on neurobiological factors, but may also be caused by other factors such as reduction in rehabilitation services [14].

Thus, increasing therapy dose, also in the chronic phase of the disease, might be a critical factor to achieve a positive outcome. Although several guidelines for upper limb rehabilitation have been recently issued $[5,10]$, the relationship between training intensity and recovery patterns is not yet fully established. Indeed, it is not fully clear how to quantify the dose increase leading to a positive outcome. Training volume, understood as the number of repetitions, seems to be a more relevant parameter of dose than just the total time allocated for therapy [9]. An important issue is how to quantify and capture this concept in a measurable parameter. Intensity of training, understood as the number of repetitions divided by the number of minutes of active therapy, might be a fundamental factor (together with amount and frequency of therapy) to quantify training efficiency. This knowledge becomes critical in order to evaluate cost-effectiveness of new technology-mediated interventions and to select the most valuable therapy procedures at the different stages of the continuum of care for stroke survivors.

\section{Virtual reality for motor rehabilitation}

Different complementary solutions have been proposed during the last decades to help increase and maintain the rehabilitation dose in the long term, mainly through continued therapy. Virtual reality (VR) based motor rehabilitation is a relatively recent approach, showing evidence of moderate effectiveness in improving upper limb and ADL function when compared to conventional therapy [15].

Many VR setups, and often generic (i.e. not developed for rehabilitation purposes) commercial off-the-shelf computer games, are used to perform a series of exercises, where patients move in front of a console and receive mostly visual feedback about their movements [16-18]. This represents a limited approach, whereby the level of immersion and potential feedback is restricted to a single sensorimotor action-perception loop: the patient moves and receives only abstract visual feedback from the screen. A rather different approach implies embodied sensorimotor feedback, where movements of the patient in the real world are reproduced as movements of an anthropomorphic avatar in the virtual environment. Under such conditions, VR allows for more elaborated sensorimotor activation, which may impact the recovery process. In particular, through sensorimotor resonance mechanisms, embodied sensorimotor feedback allows the integration of motor priming techniques and cognitive principles related to body perception and action, including mirror therapy [19] and action observation [20, 21], which have been shown to improve functional recovery and increase cortical activation of the ipsilesional side after stroke. This embodied technology can be achieved by using motion capture technology that interprets the patient's movements and provides multisensory (vision, audio, touch) feedback to the user about the movement performance. Such enriched VR experiences have been demonstrated to increase patients' motivation [22] and facilitate functional recovery by engaging appropriate neural circuits in the motor system [23].

One of the VR advantages is that it enables simulated practice of functional tasks at a higher dosage than traditional therapies [15]. Lohse and colleagues recently reviewed the duration, time and frequency scheduled for different VR and computer games interventions, but training intensity (as defined above) was no reported 
[24]. In general, authors reported an overall median of $570 \mathrm{~min}$ of VR (or computer games) therapy delivered, with duration ranging from 20 to $60 \mathrm{~min}$ per session, and 8 to 36 sessions [24]. Otherwise, intensity of training is rarely reported for VR training (see [25] for an exception). However, this is a critical factor to estimate costeffectiveness of VR-based interventions.

\section{Objectives of the study}

The present study aims at investigating the feasibility of admninistering intensive training in chronic stroke patients using a dedicated VR-based system that embeds real-time 3D motion capture and embodied visual feedback to deliver functional exercises designed to train impaired motor skills of the upper limb. Our primary goal was to assess (i) rehabilitation dose and training intensity in chronic patients. Additionally, we asked (ii) whether chronic stroke survivors improve functional outcomes of the upper limb when exposed to intensive VR-based therapy, and we measured (iii) safety and tolerance to such a technology-mediated intervention. We hypothesize that intensive VR-based rehabilitation may lead to high rehabilitation doses and functional improvement in chronic stroke survivors.

\section{Material and methods}

\section{Participants}

Ten chronic ( $>6$ months from stroke onset) outpatient stroke survivors with hemiparesis participated in the study (age: $54.9 \pm 13.1$ years; 6 females; time after stroke: 6 to 108 months; see Table 1). They were recruited from the "Clinique Romande de Réadaptation" (Sion, Switzerland) from February to October 2015. They were selected following the inclusion and exclusion criteria listed in Table 2.

\section{Experimental procedure}

This was a single-group and blinded-assessor intervention study, with a physical therapist delivering the therapy, and a second therapist carrying out the preand post-intervention assessments. The blinded assessor was not aware of the therapy details, including exercise schedule, dose or training intensity. The clinical protocol was approved by the Ethics Committee of the Canton of Valais (Switzerland). All participants provided their written informed consent prior to enrolment. They were reimbursed for their transportation expenses.

The intervention consisted of 10 one-hour training sessions of VR, with a frequency of two sessions per week over a period of 5 weeks. At each session, the participants sat in a comfortable chair with armrests in front of a table with their feet resting on the floor or on a footstool if needed. The VR system was placed on the table, leaving enough workspace for participants to complete the exercises. A physical therapist freely administered the upper limb therapy content using the VR system, selecting the task/exercise and training modality, and gradually adjusting its difficulty level (e.g. asking the participant to carry it out against gravity or gravitycompensated) according to the participant's needs and abilities, but without assisting participants physically. At each session, participants completed a series of assessments before and after the training period (see section 2.4). Besides the VR sessions, the participants were allowed to continue their usual therapy sessions and activities of daily living.

The assessor evaluated the participants at baseline (T0), post-treatment (T1) and at 4-week follow-up (T2). The baseline assessment was conducted prior to the beginning of the training. The post-treatment assessment was conducted after a 20-min break after the last training session. Follow-up assessments were completed four weeks after the end of the training (i.e., nine weeks after baseline).

\section{Virtual reality system}

The interventional device was a tabletop version of MindMotion $^{\text {Tx }}$ PRO (MindMaze SA, Switzerland), a VR-based motor rehabilitation system developed for functional

Table 1 Demographic data of participants

\begin{tabular}{lllll}
\hline Patient & Age (years) & Gender & Stroke & Time from stroke (months) \\
\hline P1 & 43 & F & Right Sylvian ischemic & 51 \\
P2 & 50 & M & Left Sylvian ischemic & 26 \\
P3 & 55 & F & Right Sylvian ischemic & 108 \\
P4 & 38 & F & Left rupture cerebral aneurysm Sylvian & 6 \\
P5 & 64 & M & Left Sylvian ischemic & 9 \\
P6 & 64 & M & Left pontine ischemic & 22 \\
P7 & 72 & M & Right Sylvian sub-cortical ischemic & 72 \\
P8 & 34 & F & Left Sylvian ischemic & 6 \\
P9 & 68 & F & Right Sylvian ischemic & 42 \\
P10 & 61 & F & Right anterior communicating artery ischemic & 54 \\
\hline
\end{tabular}


Table 2 Inclusion and exclusion criteria

\begin{tabular}{ll}
\hline Inclusion criteria & Exclusion criteria \\
\hline - Ischemic or hemorrhagic & - Participating in another \\
minor-to-moderate $(0<$ NIHSS $<16)$ & movement treatment study at the \\
stroke with hemiparesis and experi- & time of the present study \\
encing arm motor difficulties & - Severe cognitive impairment \\
• At least 6 months after stroke & (Mini Mental Status Examination \\
incident & score $<18$ points) \\
• Maximum 4 on the Medical & $\begin{array}{l}\text { - Orthopedic impairment or visual } \\
\text { disorders limiting the treatment }\end{array}$ \\
Research Council Scale (MRCS) for & $\begin{array}{l}\text { - Unable to give informed consent } \\
\text { shoulder elevation and elbow }\end{array}$ \\
flexion/extension & form \\
- 18 years and older & Risk of epileptic seizures \\
- First ever stroke & \\
\hline
\end{tabular}

training of upper limb after brain damage. Exercises of the MindMotion $^{\mathrm{TM}}$ PRO are presented in game-like scenarios designed to increase patients' motivation and therapy dose. The mobile platform is composed of a $3 \mathrm{D}$ motion tracking camera (MindMaze SA), and a touch screen with an embedded computer. The 3D motion tracking camera captures and interprets participant's movements, quantifying upper limb and trunk joints angles by using passive colored markers (Fig. 1a). For tracking of the forearm (supination and pronation) and wrist (flexion-extension, ulnar-radial deviation) movements, wireless inertial trackers using Bluetooth technology are used. These movements are then mapped to an avatar (i.e., a virtual character) in the virtual environment. The avatar, seen from a first-person or third-person perspective, reproduces the participant's movements in real time (Fig. 1), ensuring visuomotor synchrony and closed-loop via embodied visual feedback (participant identifies his/her own movements in those of the avatar). The touch screen includes a button that allows the user to switch between the therapist interface, where therapist composes and launches the exercises, and the patient interface, which displays the virtual environment for the VR exercises. Through the user interface, therapist prescribes the appropriate exercises by selecting them from the available set, indicating the body side to be used, the visual feedback modality, difficulty level and number of repetitions. The device's database stores all information related to therapy execution, therefore allowing for accurate quantification of training intensity.

\section{The rehabilitation exercises}

The system offers interactive VR exercises that engage participants' shoulder, elbow, forearm and wrist movements with various levels of difficulty. These movements are integrated into functional tasks that include pointing, reaching and grasping virtual objects. The pointing exercise consists of aiming at the center of a target with the forearm or wrist during a few seconds. In the reaching task (Fig. 1b), the participant has to extend the arm to hit virtual objects placed on a virtual table within the peripersonal space. The grasping game consists of grabbing a virtual object in the vertical plane (illustrated in Fig. 1a) and dropping it in a new location. The most solicited joint movements include: shoulder flexion/extension, shoulder horizontal abduction/adduction, shoulder internal/external rotation, and elbow flexion/ extension. Each exercise includes a variant to additionally train forearm pronation/supination and wrist flexion/extension. All exercises are played from a firstperson perspective and can be done with participants

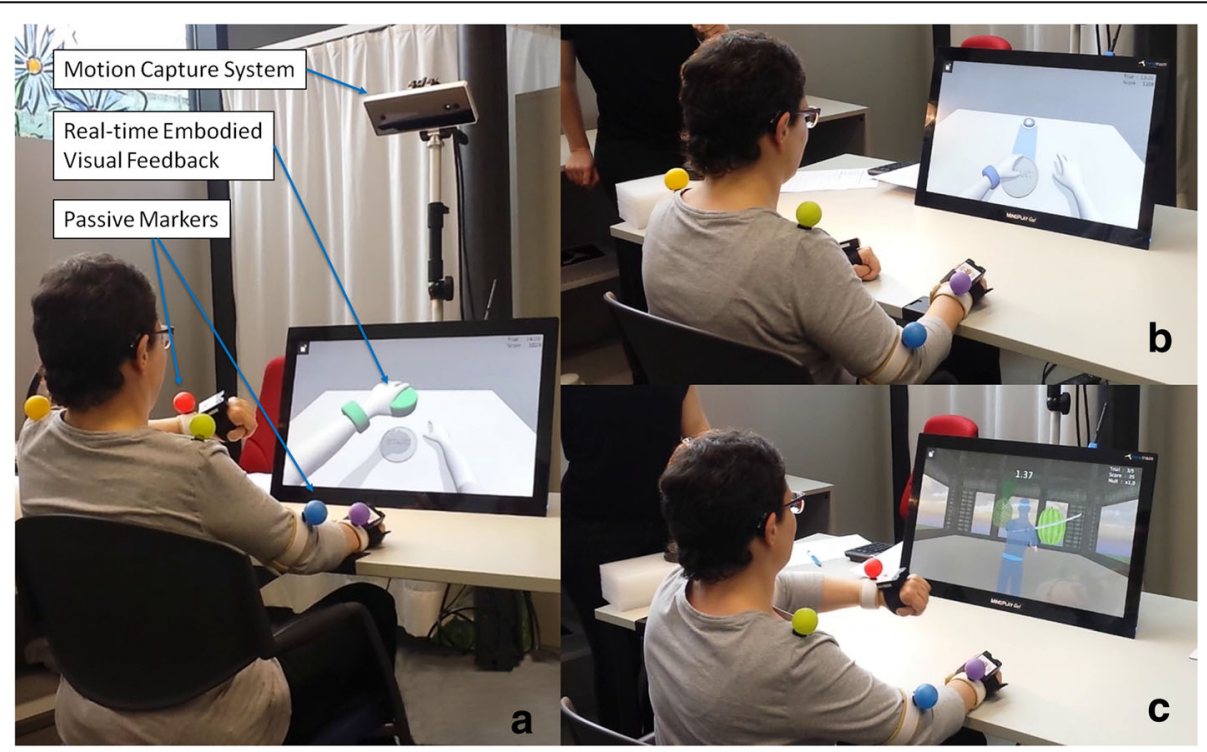

Fig. 1 a Participant performing an upper limb exercise (Grasping) with the MindMotion ${ }^{\mathrm{T} M}$ PRO technology; b Participant doing the Reaching exercise; c Participant doing a Fruitchamp exercise 
sliding their arms on the table surface, to help to compensate for gravity. When needed, therapists offered to use a small towel to ease sliding of the arm over the table surface. These tasks aim at improving movement stability, trajectory accuracy, and muscle strength against gravity. An additional exercise in an enriched scenario, where a ninja seen from a third-person perspective cuts fruits appearing on the screen, develops participants' range of motion and motor control while increasing speed and accuracy of movements of the forearm and wrist (Fig. 1c). After each repetition, participants receive a score based on their motor performance (i.e., movement stability, trajectory accuracy) as a reward for enhancing their motivation.

The system also includes a virtual mirror mode available for all exercises, where movements of the unaffected arm control the movements of the contralateral virtual arm, providing the visuomotor illusion of movement of the affected arm. Therapists were encouraged to promote activity of the affected arm using the direct mode, however they could freely select the mirror mode when appropriate, e.g. for the affected arm to get some rest if fatigue appears. Additionally, and in line with the concept of constraint-induced movement training that forces use of the affected hand [26], the virtual exercises with MindMotion ${ }^{\text {Ti }}$ PRO software allow to select the targeted arm (left/right) for the game control, so that the participant can progress only if the targeted limb is used.

\section{Outcome measures}

\section{Primary outcomes}

Rehabilitation dose and training intensity Rehabilitation dose and training intensity were quantified according to the following variables:

i. Duration of the training session, defined as the number of minutes from the beginning of the first exercise of the session to the end of the last exercise of the session.

ii. Effective training time, defined as the number of minutes a participant actively trained during each session. Breaks between exercises were excluded from this measure.

iii. Number of goal-directed movements, defined as the sum of intended movements (e.g. elbow extension to reach, shoulder internal rotation to point, elbow flexion to come back to initial position) to achieve a task, per session and in total.

iv. Number of goal-directed movements per minute of effective training time.

Importantly, the total number of goal-directed movements reflects the overall rehabilitation dose. The number of goal-directed movements per minute of effective training time yields an estimate of the intensity of the training. All the recorded times were extracted from the database of the VR system.

\section{Secondary outcomes}

Upper limb function Upper limb function was assessed with the Fugl-Meyer Assessment for Upper Extremity (FMA-UE), a stroke-specific test to measure motor impairment and determine motor recovery [27]. In chronic stroke, the minimal clinically important difference (MCID) for the overall upper limb function measured with FMA-UE is 5.25 over a maximum score of 66 [28]. FMA-UE was administered at baseline (T0), after completion of the last treatment session (T1), and at followup one month after completion of the training (T2).

Active range of motion Active range of motion (AROM) of shoulder flexion $\left(0^{\circ}\right.$ position: arm by side aligned between shoulder and hip), elbow extension $\left(0^{\circ}\right.$ position: fully extended elbow; humerus and radius aligned), wrist extension $\left(0^{\circ}\right.$ position: hand resting on table with palm facing down), forearm supination $\left(0^{\circ}\right.$ position: thumb oriented up towards ceiling) and pronation $\left(0^{\circ}\right.$ position: thumb oriented up towards ceiling) was measured with a goniometer in a standardized way (neutral zero method) [29]. This measure evaluates participant's capacity to perform isolated joint movements.

Muscle strength Muscle strength for each joint was assessed with the Modified Medical Research Council Scale (mMRCS) [30].

Functional independence Functional independence was assessed with the Functional Independence Measure (FIM; maximal score: 126), which evaluates motor function and socio-cognitive skills [31].

Pain ratings In addition to the questions related to adverse events, we measured pain level at each joint (shoulder, elbow, wrist) at the beginning of each session using an 11-point visual analog scale (VAS) [32].

AROM, mMRCS, FIM and pain VAS were administered at baseline (T0), after completion of the last treatment session (T1), and during a follow-up visit one month after completion of the training (T2).

\section{Safety and acceptance of technology}

Before and at the end of each session, participants answered 15 questions that evaluate different aspects on safety and acceptance of the technology:

Tolerance to VR intervention Q1-Q4 were related to fatigue and relaxation, comparing participant's states immediately before and after each session (Table 6). This 
comparison provided us information whether therapy sessions increased fatigue and stress levels. This information was recorded at every session.

Adverse event monitoring Q5 referred to any pain experience during the training (Table 6). This information was recorded at every session. Besides questionnaire, participants were debriefed at the end of each session.

Self-evaluation Q6 assessed self-reported movement improvements (Table 6). This information was recorded at every session.

Acceptance of technology Q7-Q8 evaluated the degree of concentration and immersion into the VR exercises. Q9 reported on the motion tracking accuracy. Q10-Q13 reflected participant's attitude towards the technology. This information was recorded at first and last sessions (Table 7).

Motivation Q14-Q15 referred to participant's motivation to continue the therapy at the hospital and at home (Table 7). This information was recorded at first and last sessions.

To quantify participant's responses, we used a 7-point colored visual scale, with participants pointing to the level that corresponded best to their state, which was translated into a 7 -point ordinal scale $(1=$ completely disagree, 7 = completely agree). After the questionnaire, participants had the chance to give any additional feedback regarding the exercises and treatment.

\section{Data analysis}

Data analysis was conducted with $R$ software [33]. We used Wilcoxon signed-rank test for the single comparisons (last vs. first session) of the rehabilitation dose and training intensity measures. We applied non-parametric Friedman test to evaluate changes in the secondary outcome measures from baseline (T0) to post-intervention (T1) and follow-up (T2). We also used Wilcoxon signed-rank test for the post-hoc analyses, and reported effect sizes ( $r$ ) [34]. Improvement rate in FMA-UE was computed as the improvement percentage with respect to the potential full recovery (i.e. 66-baseline score). Non-parametric Friedman test was also conducted to estimate any changes in fatigue and relaxation levels within sessions across the treatment. For all the analyses, we set significance level at $p<0.05$, and then applied Bonferroni correction when multiple comparisons were made. We report Median and Interquartile Range (IQR) unless otherwise specified.

\section{Results}

All ten participants completed all ten sessions of the treatment. The study lasted nine months and one week, counted from the first session of the first participant to the follow-up session of the last patient. No severe adverse events were reported. Overall, 1485 tasks were completed (Point: 20.5\%; Reach: 41.3\%; Grasp: 23.4\%; Fruitchamp: $14.9 \%$ ); only $1.35 \%$ used the mirror mode.

\section{Primary outcomes \\ Rehabilitation dose and training intensity}

Table 3 summarizes all analyzed components of the rehabilitation dose. The median duration across participants of the training sessions increased from $26.8 \mathrm{~min}$ (IQR: 20.6 to 32.7 ) in the first session to $37.2 \mathrm{~min}$ in the last session (IQR: 30.9 to 45.6; non-significant trend, $\mathrm{Z}=1.687, p=0.074$, effect size $r=0.377$ ). The total training time across all ten sessions was $403 \mathrm{~min}$ (IQR: 331 to 417). More importantly, the median effective training time per session increased from $16.5 \mathrm{~min}$ (IQR: 12.5 to 20.1) in the first session to $32.1 \mathrm{~min}$ in the last session (IQR: 23.9 to $37.9 ; \mathrm{Z}=2.701, p=0.007$, $r=0.604)$. The total effective training time provided across the ten sessions was 290 min (IQR: 246 to 329).

The median number of goal-directed movements per session increased from 212.0 (IQR: 152.0 to 301.3 ) in the first session to 476.5 in the last session (IQR: 432.3 to 637.0; $\mathrm{Z}=2.805, p=0.005, r=0.627$ ), with a maximum of 517.0 (IQR: 373.0 to 624.3) in session \#7 (Fig. 2). The total of goal-directed movements completed by patients across the ten sessions was 4713 (IQR: 3669 to 5293).

Notably, the intensity of the training, defined as the number of goal-directed movements per minute of effective training time, increased progressively from 13.2 (IQR: 11.4 to 15.9 ) in the first session to 17.3 movements in the last session (IQR: 16.6 to $18.7 ; \mathrm{Z}=2.089$, $p=0.037, r=0.467$; Fig. 2).

\section{Secondary outcomes Upper limb function}

Changes in FMA-UE scores were observed across the different assessment time points $\left(\chi^{2}(2)=9.892\right.$, $p=0.007)$. When performing a post-hoc analysis, FMAUE score increased from 42.0 (IQR 24.75 to 53.0 ) at T0 (baseline) to 44.5 at $\mathrm{T} 1$ (IQR: 26.25 to $54.75 ; \mathrm{Z}=1.552$, $p=0.131$, effect size $r=0.347$ ) and increased to 45.5 at T2 (IQR: 27.0 to $57.0 ; \mathrm{Z}=2.105, p=0.035, r=0.471$; Table 5). Participants P2 and P4 improved in FMA-UE more than the MCID at post-treatment and follow-up (P2: $47 \rightarrow 54 \rightarrow 54 ;$ P4: $17 \rightarrow 24 \rightarrow 26$ ). Participant P10 also improved over the MCID at follow-up $(54 \rightarrow 55 \rightarrow 61)$. Table 4 shows FMA-UE scores for each participant. Studies suggest that motor recovery is better captured in terms of change in functional scores, rather than of final 
Table 3 Differences in the rehabilitation dose between the first and last sessions. ${ }^{*}$ Wilcoxon signed-rank test, $p<0.05$

\begin{tabular}{|c|c|c|c|c|}
\hline & $\begin{array}{l}\text { Session \#1 } \\
\text { Median } \\
\text { (IQR) }\end{array}$ & $\begin{array}{l}\text { Session \#10 } \\
\text { Median } \\
\text { (IQR) }\end{array}$ & $\begin{array}{l}\text { Total } \\
\text { Median } \\
\text { (IQR) } \\
\end{array}$ & $\begin{array}{l}p \text {-value } \\
\text { (Session \#1 vs. \#10 }\end{array}$ \\
\hline Duration of training (minutes) & $\begin{array}{l}26.8 \\
(20.6 \text { to } 32.7)\end{array}$ & $\begin{array}{l}37.2 \\
(30.9 \text { to } 45.6)\end{array}$ & $\begin{array}{l}403 \\
\text { (331 to } 417 \text { ) }\end{array}$ & 0.074 \\
\hline Effective training time (minutes) & $\begin{array}{l}16.5 \\
(12.5 \text { to } 20.1)\end{array}$ & $\begin{array}{l}32.1 \\
(23.9 \text { to } 37.9)\end{array}$ & $\begin{array}{l}290 \\
(246 \text { to } 329)\end{array}$ & $0.007^{*}$ \\
\hline Goal-directed Movements & $\begin{array}{l}212.0 \\
(152.0 \text { to } 301.3)\end{array}$ & $\begin{array}{l}476.5 \\
(432.3 \text { to } 637.0)\end{array}$ & $\begin{array}{l}4713 \\
(3669 \text { to } 5293)\end{array}$ & $0.005^{*}$ \\
\hline $\begin{array}{l}\text { Goal-directed movements per } \\
\text { minute of Effective training time }\end{array}$ & $\begin{array}{l}13.2 \\
(11.4 \text { to } 15.9)\end{array}$ & $\begin{array}{l}17.3 \\
(16.6 \text { to } 18.7)\end{array}$ & $\mathrm{N} / \mathrm{A}$ & $0.037^{*}$ \\
\hline
\end{tabular}

endpoint [35]. Thus, we also analyzed the proportion of recovery obtained after the training and the follow-up, by calculating the score difference normalized for the maximum recovery possible. This measure better controls for individual differences at baseline and possible ceiling effect. After the VR-based intervention, the median improvement rate was of $5.3 \%$ from $\mathrm{T} 0$ to $\mathrm{T} 1$, and of $15.4 \%$ from $\mathrm{T} 0$ to $\mathrm{T} 2$. In both cases, the improvement was significantly greater than zero (Wilcoxon signedrank test; T0-T1: $p=0.038$; T0-T2: $p=0.014$ ).

\section{Active range of motion}

A significant pre-post improvement in AROM was observed for shoulder flexion $\left(\chi^{2}(2)=9.297, p=0.010\right)$, likely the joint movement solicited the most in the ensemble of VR exercises. Shoulder flexion increased from 105. $0^{\circ}$ (IQR: $63.8^{\circ}$ to $118.8^{\circ}$ ) at T0 (baseline) to $117.5^{\circ}$ (IQR: $71.3^{\circ}$ to $133.8^{\circ} ; \mathrm{Z}=1.843, p=0.065$, effect size $r=0.412$ ) at $\mathrm{T} 1$ (post-treatment) and significantly to 117.5 (IQR: $77.5^{\circ}$ to $131.3^{\circ} ; \mathrm{Z}=2.770, p=0.007$, $r=0.619)$ at $\mathrm{T} 2$ (follow-up). A positive change was also observed for forearm pronation $\left(\mathrm{X}^{2}(2)=6.889\right.$, $p=0.032$ ). Forearm pronation increased from $62.5^{\circ}$
(IQR: $0.0^{\circ}$ to $83.8^{\circ}$ ) at T0 to $87.5^{\circ}$ (IQR: $56.3^{\circ}$ to $90.0^{\circ}$; $\mathrm{Z}=2.390, p=0.027, r=0.534$ ) at $\mathrm{T} 1$ and to $87.5^{\circ}$ (IQR: $57.5^{\circ}$ to $\left.90.0^{\circ} ; \mathrm{Z}=1.714, p=0.128, r=0.383\right)$ at $\mathrm{T} 2$. No significant changes in AROM were found for the rest of upper limb movements measured (Table 5).

\section{Muscle strength}

Strength for each muscle group assessed (i.e., shoulder flexion, elbow extension, wrist extension, forearm supination, forearm pronation) showed an improvement of 0.5 points in mMRCS at follow-up compared to baseline (Table 5$)$. These changes were not statistically significant $(p>0.05)$.

\section{Functional independence}

Participants showed high levels of function both before and after the treatment. Consequently, FIM scores showed no change from baseline (121.5; IQR: 106.3 to $125.3)$ to post-treatment (121; IQR: 105 to 123 ) and to follow-up assessments (121.5; IQR: 108.8 to 123.8; $\chi^{2}(2)=0, p=1$; Table 5). No changes were observed for the six "self-care" items, which are sensitive to changes in paretic upper limb function, between baseline (41;

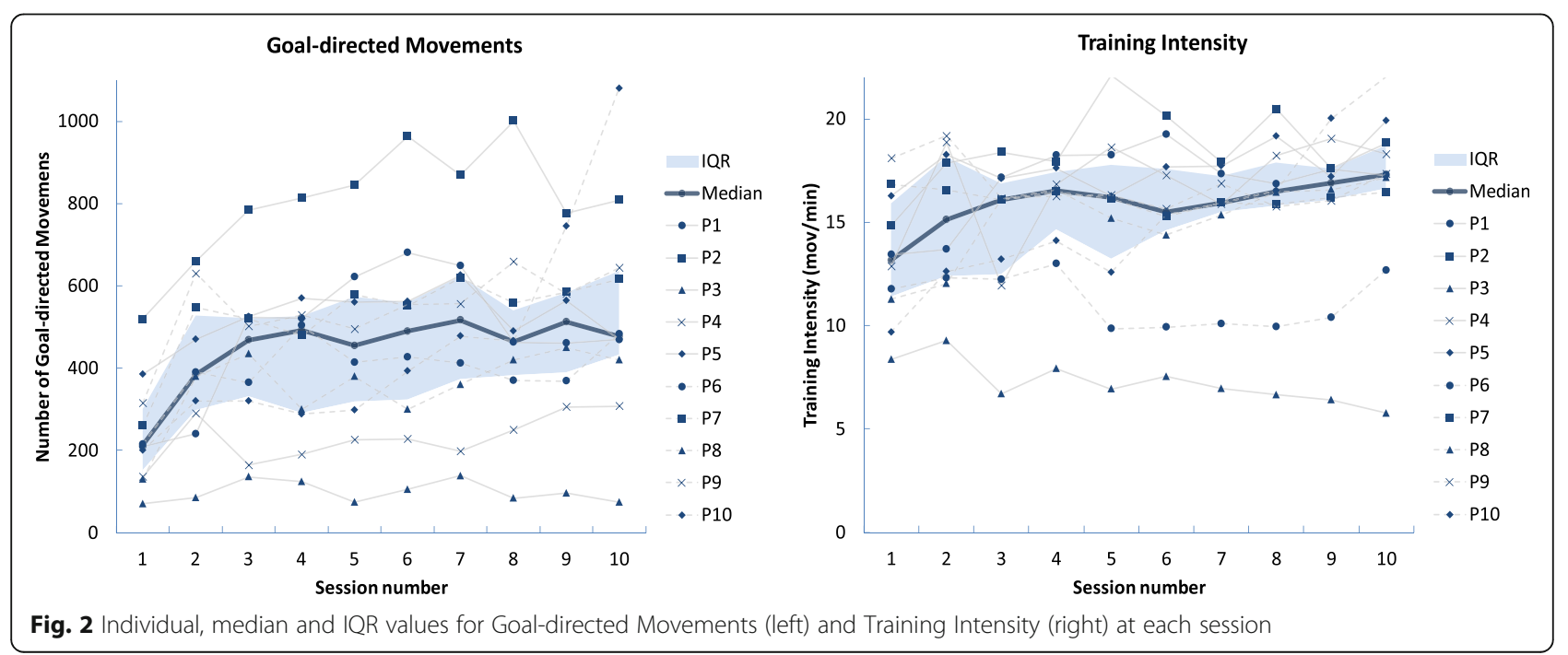


Table 4 FMA-UE and improvement rates for each participant at baseline (T0), post-assessment (T1) and follow-up (T2)

\begin{tabular}{|c|c|c|c|c|c|c|c|c|c|c|}
\hline FMA-UE & P1 & P2 & P3 & P4 & P5 & P6 & P7 & P8 & P9 & P10 \\
\hline Baseline (T0) & 36 & 47 & 55 & 17 & 21 & 37 & 57 & 18 & 50 & 54 \\
\hline Post-treatment (T1) & 33 & 54 & 55 & 24 & 23 & 38 & 58 & 17 & 51 & 55 \\
\hline Follow-up (T2) & 30 & 54 & 58 & 26 & 23 & 39 & 59 & 19 & 52 & 61 \\
\hline Improvement rate at $\mathrm{T} 1$ & $-10 \%$ & $37 \%$ & $0 \%$ & $14 \%$ & $4 \%$ & $3 \%$ & $11 \%$ & $-2 \%$ & $6 \%$ & $8 \%$ \\
\hline Improvement rate at $\mathrm{T} 2$ & $-20 \%$ & $37 \%$ & $27 \%$ & $18 \%$ & $4 \%$ & $7 \%$ & $22 \%$ & $2 \%$ & $13 \%$ & 58 \\
\hline
\end{tabular}

Table 5 Median and IQR of primary and secondary clinical outcomes at baseline (T0), post-treatment (T1) and follow-up (T2). ${ }^{+}$Friedman test, $p<0.05 ;{ }^{*}$ Wilcoxon signed-rank test, $p<0.025$ (Bonferroni corrected)

\begin{tabular}{|c|c|c|c|c|c|c|}
\hline & \multirow{2}{*}{$\begin{array}{l}\text { Baseline (T0) } \\
\text { Median } \\
\text { (IQR) }\end{array}$} & \multirow{2}{*}{$\begin{array}{l}\text { Post-treatment } \\
\text { (T1) } \\
\text { Median } \\
\text { (IQR) }\end{array}$} & \multirow{2}{*}{$\begin{array}{l}\text { Follow-up (T2) } \\
\text { Median } \\
\text { (IQR) }\end{array}$} & \multirow{2}{*}{$\begin{array}{l}\text { Friedman test } \\
\text { p-value }\end{array}$} & \multicolumn{2}{|c|}{ Wilcoxon signed-rank test } \\
\hline & & & & & $\begin{array}{l}\text { p-value } \\
\text { T0 to T1 }\end{array}$ & $\begin{array}{l}\mathrm{p} \text {-value } \\
\text { T0 to T2 }\end{array}$ \\
\hline FMA-UE & $\begin{array}{l}42.0 \\
(24.75 \text { to } 53.00)\end{array}$ & $\begin{array}{l}44.5 \\
(26.25 \text { to } 54.75)\end{array}$ & $\begin{array}{l}45.5 \\
(27.0 \text { to } 57.0)\end{array}$ & $0.007^{+}$ & 0.131 & 0.035 \\
\hline \multicolumn{7}{|l|}{ AROM (in ${ }^{\circ}$ ) } \\
\hline Shoulder flexion & $\begin{array}{l}105.0 \\
\text { (63.8 to 118.8) }\end{array}$ & $\begin{array}{l}117.5 \\
\text { (71.3 to } 133.8)\end{array}$ & $\begin{array}{l}117.5 \\
\text { (77.5 to } 131.3 \text { ) }\end{array}$ & $0.010^{+}$ & 0.065 & $0.007^{*}$ \\
\hline Elbow extension & $\begin{array}{l}-8.5 \\
(-10.0 \text { to }-1.3)\end{array}$ & $\begin{array}{l}-7.5 \\
(-10.0 \text { to } 0.0)\end{array}$ & $\begin{array}{l}-5.0 \\
(-10 \text { to } 0)\end{array}$ & 0.420 & & \\
\hline Wrist extension & $\begin{array}{l}35.0 \\
\text { (6.3 to 55.0) }\end{array}$ & $\begin{array}{l}37.5 \\
\text { (8.8 to 55.0) }\end{array}$ & $\begin{array}{l}45.0 \\
\text { ( } 22.5 \text { to } 60.0)\end{array}$ & 0.095 & & \\
\hline Forearm supination & $\begin{array}{l}62.5 \\
\text { (5.0 to } 78.8)\end{array}$ & $\begin{array}{l}57.5 \\
\text { (12.5 to } 83.8)\end{array}$ & $\begin{array}{l}67.5 \\
\text { (12.5 to } 80.0)\end{array}$ & 0.131 & & \\
\hline Forearm pronation & $\begin{array}{l}62.5 \\
(0.0 \text { to } 83.8)\end{array}$ & $\begin{array}{l}87.5 \\
\text { (56.3 to } 90.0)\end{array}$ & $\begin{array}{l}87.5 \\
\text { (57.5 to } 90.0)\end{array}$ & $0.032^{+}$ & 0.027 & 0.128 \\
\hline \multicolumn{7}{|l|}{ mMRCS } \\
\hline Shoulder flexion & $\begin{array}{l}3 \\
\text { (3.0 to } 3.8 \text { ) }\end{array}$ & $\begin{array}{l}3.5 \\
\text { (3.0 to } 4.0 \text { ) }\end{array}$ & $\begin{array}{l}3.5 \\
\text { (3.0 to } 4.0)\end{array}$ & 0.156 & & \\
\hline Elbow extension & $\begin{array}{l}2.5 \\
\text { (2.0 to } 3.0 \text { ) }\end{array}$ & $\begin{array}{l}3 \\
\text { (2.3 to } 3.8 \text { ) }\end{array}$ & $\begin{array}{l}3 \\
\text { (2.3 to } 4.0)\end{array}$ & 0.074 & & \\
\hline Wrist extension & $\begin{array}{l}3 \\
\text { (1.5 to } 4.0)\end{array}$ & $\begin{array}{l}3 \\
\text { (2.3 to } 4.0)\end{array}$ & $\begin{array}{l}3.5 \\
\text { (2.3 to } 4.0)\end{array}$ & 0.174 & & \\
\hline Forearm supination & $\begin{array}{l}3 \\
\text { (1.3 to } 4.0)\end{array}$ & $\begin{array}{l}3.5 \\
(1.5 \text { to } 4.0)\end{array}$ & $\begin{array}{l}3.5 \\
(1.5 \text { to } 4.0)\end{array}$ & 0.424 & & \\
\hline Forearm pronation & $\begin{array}{l}3 \\
\text { (0.5 to } 4.0)\end{array}$ & $\begin{array}{l}3.5 \\
\text { ( } 2.3 \text { to } 4.0 \text { ) }\end{array}$ & $\begin{array}{l}3.5 \\
\text { (3.0 to } 4.0 \text { ) }\end{array}$ & 0.350 & & \\
\hline FIM & $\begin{array}{l}121.5 \\
\text { (106.3 to } 125.3)\end{array}$ & $\begin{array}{l}121 \\
\text { (105 to } 123)\end{array}$ & $\begin{array}{l}121.5 \\
\text { (108.8 to } 123.8)\end{array}$ & 1 & & \\
\hline \multicolumn{7}{|l|}{ VAS } \\
\hline Shoulder flexion & $\begin{array}{l}0 \\
\text { (0 to 6) }\end{array}$ & $\begin{array}{l}1 \\
\text { (0 to } 2)\end{array}$ & $\begin{array}{l}0 \\
\text { (0 to } 1.75)\end{array}$ & 0.368 & & \\
\hline Elbow extension & $\begin{array}{l}0 \\
\text { (0 to 4) }\end{array}$ & $\begin{array}{l}0 \\
(0 \text { to } 0)\end{array}$ & $\begin{array}{l}0 \\
(0 \text { to } 0)\end{array}$ & 0.146 & & \\
\hline Wrist extension & $\begin{array}{l}0 \\
(0 \text { to } 4)\end{array}$ & $\begin{array}{l}0 \\
(0 \text { to } 0)\end{array}$ & $\begin{array}{l}0 \\
(0 \text { to } 0)\end{array}$ & $0.0498^{+}$ & 0.103 & 0.103 \\
\hline Forearm supination & $\begin{array}{l}0 \\
\text { (0 to } 0)\end{array}$ & $\begin{array}{l}0 \\
(0 \text { to } 0)\end{array}$ & $\begin{array}{l}0 \\
(0 \text { to } 0)\end{array}$ & 0.135 & & \\
\hline Forearm pronation & $\begin{array}{l}0 \\
(0 \text { to } 0)\end{array}$ & $\begin{array}{l}0 \\
(0 \text { to } 0)\end{array}$ & $\begin{array}{l}0 \\
(0 \text { to } 0)\end{array}$ & 0.368 & & \\
\hline
\end{tabular}


IQR: 37.5 to 42 ), post-treatment (41; IQR: 37 to 42$)$ and follow-up assessments (41.5; IQR: 38.3 to $42 ; \chi^{2}(2)=4$, $p=0.135)$.

\section{Pain ratings}

Overall, pain levels as measured by the VAS scale at baseline, post-treatment, and follow-up were low all across the treatment, confirming no negative longlasting effects due to the VR-based intervention. Importantly, pain levels did not increase during the treatment period for any joint (all $\mathrm{p}>0.05$; Table 5 ), meaning that physical activity carried out during VR intervention was well tolerated.

\section{Relationship between motor improvement and training intensity}

We explored any eventual relationship between the rehabilitation dose or training intensity and the clinical outcomes capturing any significant change after the intervention, namely FMA-UE and AROM of shoulder flexion. We could not establish any relationship between the total active therapy time with either pre-post changes in FMA-UE $\left(\mathrm{R}^{2}=0.011\right)$ or AROM of shoulder flexion $\left(R^{2}=0.027\right)$. The total dose of goal-directed movements could not explain the changes either in FMA-UE $\left(\mathrm{R}^{2}=0.058\right)$ or in AROM of shoulder flexion $\left(R^{2}=0.017\right)$. Similarly, an examination of the median training intensity achieved by each patient did not appear to be able to predict changes in FMA-UE $\left(\mathrm{R}^{2}=0.115\right)$ and AROM of shoulder flexion $\left(R^{2}=0.016\right)$. Importantly, however, the increase in training intensity observed between the first and last sessions partially explained the changes in AROM of shoulder flexion $\left(\mathrm{R}^{2}=0.187, p=0.212\right)$, a relationship that became stronger and significant at the follow-up assessment $\left(R^{2}=0.598, p=0.009\right.$; Fig. 3$)$. Thus, the more patients increased their training across sections, the better the functional outcome. This relationship was specific for shoulder flexion, i.e. the targeted joint in most of the VR activities, but it was not present for general upper limb function, as captured by FMA-UE scores $\left(R^{2}=0.018\right)$.

\section{Safety and acceptance of technology Tolerance to VR intervention}

All participants started every session with similar and low levels of fatigue (median score: 1 ; IQR: 1 to 3.8 ; $X^{2}(9)=7.730, p=0.562$; Table 6). When comparing the level of fatigue before (Q1) and after (Q3) each session, we found no statistical difference $\left(X^{2}(19)=18.137\right.$, $p=0.513)$. However, the median level of fatigue in session \#2 was moderate (median score: 5.5 ; IQR: 1.5 to 6; $\mathrm{Z}=2.545, p=0.01$, effect size $r=0.569)$. This occasional increase in fatigue may be related to the

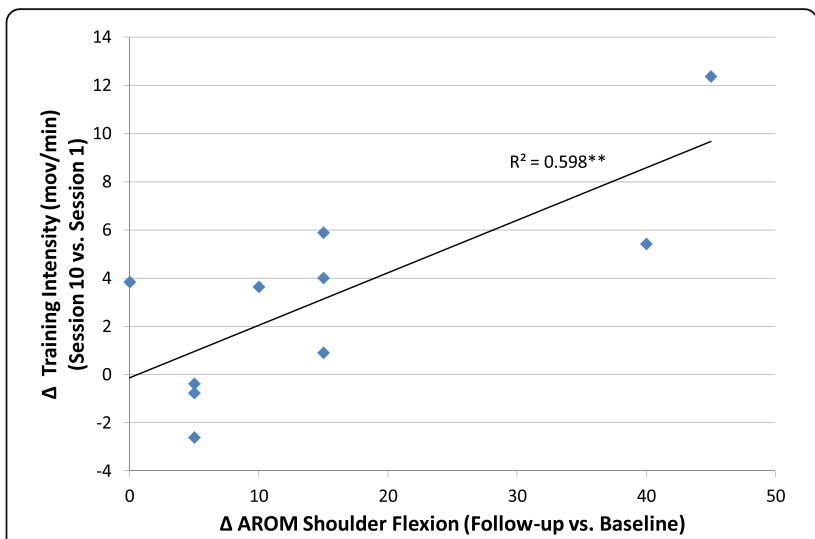

Fig. 3 Scatter plot and linear regression between changes in training intensity (session 10 vs. session 1) and changes in AROM of shoulder flexion scores (follow-up vs. baseline). ** Wilcoxon signedrank test, $p<0.01$

considerable increase in the rehabilitation dose from session \#1 to session \#2, once participants assimilated the technology (see Fig. 2). Regarding relaxation (stress) levels, participants came to each session with similar and high levels of relaxation (median score: 7; IQR: 5.3 to $7 ; \chi^{2}(9)=9.203, p=0.419$; Table 6). When comparing the relaxation level before (Q2) and after (Q4) each session, we observed no difference $\left(\chi^{2}(19)=25.386\right.$, $p=0.148)$, meaning that the intensive VR intervention did not increase participants' stress.

\section{Adverse event monitoring}

In addition to overall pain ratings at baseline and posttreatment, participants reported any eventual pain felt at the level of the upper limbs and trunk during the training (Q5; Table 6). Self-reported pain was kept low, with no significant changes across sessions $\left(\chi^{2}(9)=8.911\right.$, $p=0.446)$. Three adverse events were reported. Participant $\mathrm{P} 1$ reported increased pain in the shoulder area before the training (from session \#7 onwards). Debriefing with the participant and her usual therapist could not reveal the cause of that pain. Participant P4 was administered Botox in upper and lower limbs the day before session \#4, which led to higher level of pain in subsequent sessions. Participant P3 was particularly sensitive to screen exposure and needed headache medication. For this patient, the duration of the therapy sessions was reduced to $30 \mathrm{~min}$.

\section{Self-evaluation}

Participants reported a continuous feeling of improvement on mobility (Q6) across the sessions $\left(\chi^{2}(9)=8.037, p=0.530\right.$; Table 6). This self-reported improvement significantly increased from 4 (IQR: 1.5 to 6.3) in the first session to 7 (IQR: 5.3 to 7; 
Table 6 Evolution of questionnaire scores related to Safety aspects across sessions

\begin{tabular}{|c|c|c|c|c|c|c|c|c|c|c|}
\hline \multirow[t]{2}{*}{ Questions } & \multicolumn{10}{|l|}{ Session \# } \\
\hline & 1 & 2 & 3 & 4 & 5 & 6 & 7 & 8 & 9 & 10 \\
\hline \multicolumn{11}{|l|}{ Tolerance to VR intervention } \\
\hline $\begin{array}{l}\text { Q1: Before the session, } \\
\text { how tired do you feel? }\end{array}$ & $\begin{array}{l}1 \\
\text { (1 to } 3.8)\end{array}$ & $\begin{array}{l}1 \\
\text { (1 to } 2.5)\end{array}$ & $\begin{array}{l}1.5 \\
\text { (1 to } 2.8)\end{array}$ & $\begin{array}{l}2 \\
(1 \text { to } 3)\end{array}$ & $\begin{array}{l}2 \\
(1 \text { to } 4)\end{array}$ & $\begin{array}{l}1 \\
\text { (1 to } 4)\end{array}$ & $\begin{array}{l}3.5 \\
(1 \text { to } 5)\end{array}$ & $\begin{array}{l}3 \\
(1.5 \text { to } 5.8)\end{array}$ & $\begin{array}{l}1 \\
\text { (1 to } 4.5)\end{array}$ & $\begin{array}{l}1 \\
\text { (1 to } 2.5)\end{array}$ \\
\hline $\begin{array}{l}\text { Q3: After the session, } \\
\text { how tired do you feel? }\end{array}$ & $\begin{array}{l}1 \\
\text { (1 to } 5.8)\end{array}$ & $\begin{array}{l}5.5 \\
(1.5 \text { to } 6)\end{array}$ & $\begin{array}{l}1 \\
(1.5 \text { to } 6)\end{array}$ & $\begin{array}{l}2 \\
\text { (1 to } 5)\end{array}$ & $\begin{array}{l}2 \\
(1 \text { to } 5)\end{array}$ & $\begin{array}{l}2 \\
(1 \text { to } 6)\end{array}$ & $\begin{array}{l}3.5 \\
\text { (1 to } 5.8)\end{array}$ & $\begin{array}{l}3.5 \\
\text { (1.3 to } 6)\end{array}$ & $\begin{array}{l}2.5 \\
\text { (1 to } 5.8)\end{array}$ & $\begin{array}{l}2 \\
\text { (1 to } 5.8)\end{array}$ \\
\hline $\begin{array}{l}\text { Q2: Before the session, } \\
\text { how relaxed do you feel? }\end{array}$ & $\begin{array}{l}7 \\
\text { (5.3 to } 7)\end{array}$ & $\begin{array}{l}7 \\
\text { (7 to } 7)\end{array}$ & $\begin{array}{l}7 \\
\text { (7 to } 7)\end{array}$ & $\begin{array}{l}7 \\
\text { (7 to } 7)\end{array}$ & $\begin{array}{l}7 \\
(7 \text { to } 7)\end{array}$ & $\begin{array}{l}7 \\
\text { (7 to } 7)\end{array}$ & $\begin{array}{l}7 \\
\text { (7 to } 7)\end{array}$ & $\begin{array}{l}7 \\
\text { (7 to } 7)\end{array}$ & $\begin{array}{l}7 \\
\text { (7 to } 7)\end{array}$ & $\begin{array}{l}7 \\
(7 \text { to } 7)\end{array}$ \\
\hline $\begin{array}{l}\text { Q4: During the session, } \\
\text { how relaxed did you feel? }\end{array}$ & $\begin{array}{l}7 \\
\text { (6.3 to } 7)\end{array}$ & $\begin{array}{l}7 \\
(7 \text { to } 7)\end{array}$ & $\begin{array}{l}6 \\
(4 \text { to } 7)\end{array}$ & $\begin{array}{l}7 \\
\text { (6.3 to } 7)\end{array}$ & $\begin{array}{l}7 \\
\text { (7 to } 7)\end{array}$ & $\begin{array}{l}7 \\
(4 \text { to } 7)\end{array}$ & $\begin{array}{l}7 \\
\text { (6.3 to } 7)\end{array}$ & $\begin{array}{l}7 \\
(6 \text { to } 7)\end{array}$ & $\begin{array}{l}7 \\
\text { (5.3 to } 7)\end{array}$ & $\begin{array}{l}7 \\
(6.3 \text { to } 7)\end{array}$ \\
\hline \multicolumn{11}{|l|}{ Adverse event monitoring } \\
\hline $\begin{array}{l}\text { Q5: During the exercises, } \\
\text { did you feel any unusual pain } \\
\text { (e.g. stronger) at the level of the } \\
\text { upper limbs (arms, joints, hands) } \\
\text { or the trunk? }\end{array}$ & $\begin{array}{l}1 \\
\text { (1 to } 1.8)\end{array}$ & $\begin{array}{l}1 \\
\text { (1 to } 2.5)\end{array}$ & $\begin{array}{l}1 \\
(1 \text { to } 1)\end{array}$ & $\begin{array}{l}3 \\
(1 \text { to } 5)\end{array}$ & $\begin{array}{l}1 \\
(1 \text { to } 3)\end{array}$ & $\begin{array}{l}2 \\
\text { (1 to } 3)\end{array}$ & $\begin{array}{l}1.5 \\
(1 \text { to } 5)\end{array}$ & $\begin{array}{l}3.5 \\
(1 \text { to } 5.8)\end{array}$ & $\begin{array}{l}1 \\
\text { (1 to } 1.8)\end{array}$ & $\begin{array}{l}1 \\
\text { (1 to } 4.5)\end{array}$ \\
\hline \multicolumn{11}{|l|}{ Self-evaluation } \\
\hline $\begin{array}{l}\text { Q6: After the session, do you } \\
\text { feel any improvement of you } \\
\text { movements } \\
\text { (e.g., larger movements, } \\
\text { more precise, etc.)? }\end{array}$ & $\begin{array}{l}4 \\
\text { (1.5 to } 6.3 \text { ) }\end{array}$ & $\begin{array}{l}4.5 \\
\text { (4 to } 5.8 \text { ) }\end{array}$ & $\begin{array}{l}6 \\
\text { (4.3 to } 7 \text { ) }\end{array}$ & $\begin{array}{l}6 \\
\text { (3.5 to } 7 \text { ) }\end{array}$ & $\begin{array}{l}6 \\
\text { (5 to } 7)\end{array}$ & $\begin{array}{l}6 \\
\text { (4.5 to } 6.8 \text { ) }\end{array}$ & $\begin{array}{l}5.5 \\
\text { (5 to 6) }\end{array}$ & $\begin{array}{l}6 \\
\text { (4.5 to } 7 \text { ) }\end{array}$ & $\begin{array}{l}6 \\
(4 \text { to } 6)\end{array}$ & $\begin{array}{l}7 \\
\text { (5.3 to } 7 \text { ) }\end{array}$ \\
\hline
\end{tabular}

$\mathrm{Z}=2.136, p=0.027$, effect size $r=0.478)$ in the last session (Table 7).

\section{Acceptance of technology}

From the first session on, participants showed high levels of concentration (Q7; median score: 7, IQR: 7 to 7) and immersion (Q8; median score of feeling at hospital environment: 1 , IQR: 1 to 1 ), even forgetting that they were at the hospital (Table 7). Participants identified to a great extent their movements corresponding to those of the avatar (Q9; median score: 6, IQR: 5.3 to 7), and this perception was maintained across sessions, meaning that the self-identification with avatar's movements was kept constant (Table 7). Participants liked to a great extent performing the exercises (Q10; median score: 5, IQR: 4 to 7), and were comfortable with the demanded movements (Q11; median score: 7, IQR: 7 to 7) while being aware of the rehabilitative intention of the exercises (Q12; median score: 5, IQR: 4.5 to 7). At the end of the treatment, they also reported some interest in having an improvement in the graphical quality of the avatar (Q13; median score: 4, IQR: 1.3 to 6.8). In all cases, this acceptance of technology was intact after ten sessions of training (Table 7; all $p>0.05$ ).

\section{Motivation}

Participants explicitly expressed their willingness to continue with the VR training both at hospital (Q14; median score after session \#1: 6, IQR: 4 to 7) and at home (Q15; median score after session \#1: 7, IQR: 4.3 to 7), confirming their adherence to the VR intervention (Table 7). These levels of motivation were maintained intact after ten sessions of training $(\mathrm{p}>0.05)$.

\section{Discussion}

\section{Primary outcomes}

The results of this pilot study on chronic stroke show that dedicated VR-based functional training of the upper limb is able to provide high rehabilitation doses, both in terms of active training time and repetitions per session (i.e., training intensity). Participants received a total of 290 min of active VR-based functional training of the upper extremity, with a total duration of the training sessions of $403 \mathrm{~min}$. The median duration of the training session (including breaks and time between exercises) continuously increased up to $37.2 \mathrm{~min}$ in the last session, which approaches the therapy target of rehabilitation guidelines [10]. More importantly, after participants had become familiarized with the system (mostly during the first session), the VR system allowed for very efficient training sessions, with up to $32.1 \mathrm{~min}$ of effective physical activity of the upper limb in the last session. The rest of the time was dedicated to the selection of the exercises composing the session and the pauses between exercises. This translates into an efficiency rate (relation between time of therapy session and time spent in active therapy) of $86.3 \%$ for the VR-based intervention. This result supports recent evidence proving that VR-based treatments after stroke can be $10 \%$ more 
Table 7 Acceptance of technology, motivation and self-evaluation questions in the first and last sessions. ${ }^{*}$ Wilcoxon signed-rank test, $p<0.05$

\begin{tabular}{|c|c|c|c|}
\hline Questions & $\begin{array}{l}\text { First Session } \\
\text { Median(IQR) }\end{array}$ & $\begin{array}{l}\text { Last Session } \\
\text { Median(IQR) }\end{array}$ & $\begin{array}{l}\text { Wilcoxon test } \\
p \text {-value }\end{array}$ \\
\hline \multicolumn{4}{|l|}{ Self-evaluation } \\
\hline $\begin{array}{l}\text { Q6: After the session, do you feel any improvement of you movements } \\
\text { (e.g., larger movements, more precise, etc.)? }\end{array}$ & $\begin{array}{l}4 \\
(1.5 \text { to } 6.3)\end{array}$ & $\begin{array}{l}7 \\
(5.3 \text { to } 7)\end{array}$ & $0.027^{*}$ \\
\hline \multicolumn{4}{|l|}{ Acceptance of technology } \\
\hline Q7: During the exercises, were you concentrated on the task? & (7 to 7$)$ & $\begin{array}{l}7 \\
\text { (7 to } 7)\end{array}$ & 0.786 \\
\hline $\begin{array}{l}\text { Q8: During the exercises, did you have the feeling of being in the } \\
\text { hospital room? }\end{array}$ & $\begin{array}{l}1 \\
(1 \text { to } 1)\end{array}$ & $\begin{array}{l}1 \\
(1 \text { to } 1.8)\end{array}$ & 0.103 \\
\hline Q9: Did the movements of the character reflect your movements? & $\begin{array}{l}6 \\
(5.3 \text { to } 7)\end{array}$ & $\begin{array}{l}6.5 \\
(5.3 \text { to } 7)\end{array}$ & 0.546 \\
\hline $\begin{array}{l}\text { Q10: During the exercises, did you feel comfortable with the } \\
\text { requested movements? }\end{array}$ & $\begin{array}{l}5 \\
(4 \text { to } 7)\end{array}$ & $\begin{array}{l}7 \\
(6 \text { to } 7)\end{array}$ & 0.090 \\
\hline Q11: Did you like the exercises? & (7 to 7$)$ & $\begin{array}{l}7 \\
\text { (7 to } 7)\end{array}$ & 0.317 \\
\hline Q12: Did you have the impression of doing rehabilitation exercises? & (4.5 to 7$)$ & $\begin{array}{l}7 \\
(3 \text { to } 7)\end{array}$ & 0.706 \\
\hline Q13: Would you like the character to look more realistic? & $\begin{array}{l}1 \\
\text { (1 to } 4.8)\end{array}$ & $\begin{array}{l}4 \\
\text { (1.3 to } 6.8 \text { ) }\end{array}$ & 0.438 \\
\hline \multicolumn{4}{|l|}{ Motivation } \\
\hline Q14: Would you like to spend more time doing the exercises at the hospital? & $\begin{array}{l}6 \\
\text { (4 to } 7)\end{array}$ & $\begin{array}{l}7 \\
\text { (3.3 to } 7 \text { ) }\end{array}$ & 0.595 \\
\hline Q15: Would you like to continue doing the exercises at home? & $\begin{array}{l}7 \\
\text { (4.3 to } 7 \text { ) }\end{array}$ & $\begin{array}{l}7 \\
\text { (5.3 to } 7 \text { ) }\end{array}$ & 1.000 \\
\hline
\end{tabular}

efficient (i.e., higher activity rate) than conventional therapy (77\% vs. $67 \%$ of total therapy time), $20 \%$ ( $81 \%$ vs. 61\%) for severely impaired patients [25].

Animal studies suggest that 400-600 repetitions per day of functional tasks are required to induce structural neurological changes [36]. In our study, participants completed a median of 4713 goal-directed movements (which represented 1834 task repetitions). This translates to an average of 471 movements (183 tasks) completed per session, which represents a quantitatively higher dose as compared to average functional upper extremity repetitions $(45 \pm 13)$ provided in outpatient clinical practice [37]. Indeed, recent studies show that the standard dose can be increased with intensive, highrepetition programs [36]. Technology-mediated interventions such as virtual reality [15] and robotic platforms [38] have demonstrated higher dose efficiency. In the present study, VR-mediated training delivered up to 17 goal-directed movements per minute ( 8-9 completed tasks per minute), a training intensity 10-15 times higher as in standard therapy [39].

\section{Secondary outcomes}

Participants improved in FMA-UE score, with an overall $15.4 \%$ improvement rate at follow-up. Importantly, three patients improved beyond MCID, meaning that the VR- based intervention may have contributed to further clinical improvement even in a late chronic phase. Our results bring further evidence of how highly intensive upper limb training with specific shoulder and arm tasks, delivered by means of a embodied VR system, may help improve AROM for the shoulder flexion in moderate-to-severe chronic stroke patients. This is in line with a recent study that has reported AROM improvements in chronic stroke using VR-based training of moderate intensity (72 repetitions per session), especially in patients with mild upper limb motor deficits [40].

We note that FIM scores did not change after the intervention. This is likely due to the high-level of functional independence already achieved by patients at baseline (median value was 121 out of 126). Another factor could be the fact that residual deficits on chronic patients usually remain for distal and more complex finger movements, which are not targeted by the current VR exercises. Interestingly, a large study involving 376 patients who received $40 \mathrm{~h}$ of training in 4 weeks did report an increase in FIM scores for both a VR group and a conventional therapy group, with the VR group improving significantly more than the conventional therapy group [41]. Thus, longer and/or more specific upper limb training may be necessary to elicit positive FIM changes in chronic stroke patients. 
We found that the improvements in AROM of shoulder flexion observed after the intervention, and particularly at the follow-up assessment, could be partially explained by the increase in training intensity across sessions, but not by the rehabilitation dose per se (neither in number of movements or time spent in the training). This preliminary finding seems to be in line with the recommendations of the recently formed Stroke Recovery and Rehabilitation Roundtable, which advocates that "recovery trials need to consider serially applied kinematic/ kinetic measurements alongside clinical assessments to distinguish between restitution and compensation. A core set of kinetics and kinematic outcomes needs to be established" [42]. Within this context, VR systems, in particular motion capture technology, can help quantify changes in motor recovery in an objective fashion. Indeed, kinematic analyses of movement quality (based on high-quality motion tracking recordings) have been strongly advocated to be incorporated into clinical assessments as they may capture better changes in motor control [43, 44].

Embodied technology has been recently proposed for neuroprosthetics [45], and treatment of different pathologies, such as pain management [46-48] or eating disorders [49]. In the present study, we used a novel VR system for motor rehabilitation after stroke that provides embodied visuomotor feedback. In this regard, a randomized clinical trial with stroke patients has shown that VR-mediated embodied feedback for gait training may entrain several brain areas (probably encompassing the mirror neuron system) involved in motor planning and learning, thus leading to an enhanced motor performance [50]. In this context, VR has the unique potential to manipulate visual feedback of the movement made by the participant, in a way which potentially allows the selection of patterns of sensorimotor coherence aimed at activating specific sensorimotor brain circuits (e.g., action observation system [51] and other monitoring systems [52]). The individual contributions of the different priming techniques and cognitive principles included in the provided feedback were beyond the scope of this study and need to be addressed in further studies using dedicated designs.

The results of the present study suggest that it is possible to improve functional skills of the upper limb in stroke survivors with intensive training, even in the early chronic (6 months post stroke) and later chronic phases (54 months post stroke) [13]. However, secondary outcomes did not show clinical improvements after $403 \mathrm{~min}$ of training delivered (290 min effective training time). Thus, besides delivery of high training intensity, higher rehabilitation volumes are required to affect FMA and FIM scores in chronic stroke patients who still present functional deficits at everyday life activities. Further studies with stratified groups and different motor assessments could also help to identify (i) the patient profiles that benefit the most from this embodied VR technology, and (ii) the motor outcomes that capture best the eventual improvements.

\section{Safety and acceptance of technology}

Participants reported low levels of fatigue and stress generated during the training sessions. Despite the fact that the rehabilitation dose and intensity increased, especially from session \#2 onwards, the level of fatigue did not. No serious adverse event was reported in the present study. This is very likely because the VR exercises were specifically designed for neurorehabilitation purposes by clinicians and physical therapists, and were validated with acute stroke patients before proceeding to this study $[53,54]$. This approach differentiates the current embodied VR device from other attempts to adopt computer games for stroke rehabilitation, whereby consumer video consoles are used to provide motor training $[17,18]$. Approaches based on the adoption of off-the-shelf, not clinically customized, solutions have serious limitations, in that therapy objectives are not taken into account, with the type and level of activities not being tuned to stroke patients' residual abilities. In a recent study that used off-the-shelf, nonadapted, videogames for upper extremity training in subacute stroke [17], and with similar training doses delivered, participants reported adverse events such as dizziness $(15 \%)$, headaches $(13 \%)$ or nausea $(6 \%)$.

Motivation and engagement are intrinsic component of VR- and videogame-based interventions in stroke rehabilitation [55]. They are related not only to compliance and adherence to rehabilitation programs, but they also influence intervention outcomes [24]. In the current study, participants showed the highest levels of adherence to the rehabilitation program and motivation to continue therapy both at hospital and at home. This may relate to the very high levels of self-perceived improvement in mobility reported by participants at the end of the treatment. Importantly, during the debriefing several participants reported higher self-confidence levels at activities of daily living at home, with more use of the affected arm, therefore reducing non-learned use effect. This catalyzing effect may have contributed to the observed functional improvements during the follow-up assessment.

\section{Limitations of the study}

Besides the assessment of the primary outcome (training intensity and dose), this pilot study included the collection of several clinical outcomes. Within this regard, the study presents several limitations, the most important being the lack of a control group and a relatively small 
sample size, which undermine the possibility of providing evidence on therapy effectiveness. The level of physical activity of participants (or inactivity, in particular of the affected limb) prior to the intervention could also not be assessed. This is particularly critical in chronic stroke research, as patients could be functioning at a level below their full potential due to disuse. The duration of the training sessions provided in this study, and consequently the delivered dose, may have been affected by the dependence on the outpatient transportation service, planned for one hour after the session started. Training schedules (twice a week) were also adapted to both outpatient population and physical therapist availability.

\section{Conclusion}

This pilot study has shown the feasibility and safety of a specific and intensive functional training of upper extremity in chronic stroke survivors with a dedicated VR system for neurorehabilitation and based on closed visuomotor loop via embodied visual feedback. The rehabilitation dose was continuously increased, adjusting to patients' needs to maximize the training efficacy. Functional and motor outcomes suggest that highly intensive VR training may be beneficial for breaking the "plateau" of functional recovery in chronic stroke. To further assess the potential of such task-specific VR-based training (as compared to standard of care) for upper extremity rehabilitation in people with acute stroke, another study with intensive intervention (five times a week for four weeks) and fully monitoring of dose parameters is underway.

\section{Acknowledgements}

The authors thank Ron Vollen for his assistance in the selection of the clinical outcomes, Cyntia Duc for the revision of a previous version of the manuscript, and Solange Seppey for her support in literature documentation.

\section{Funding}

This study was partially sponsored by MindMaze SA.

\section{Availability of data and materials}

Raw data is available from the corresponding author on reasonable request.

\section{Authors' contributions}

DPM, GG, TS, PV, TT, OB and JdRM conceived of the study, participated in developing the design of the study, and results interpretation. OCH and AS also contributed to results interpretation. DPM, OC, GG and AS drafted and critically appraised the manuscript. DPM, OC, GG and TS participated in data collection. DPM, OC, GG and AS led the data analysis. OC, TS and PV coordinated patient recruitment. All authors read and approved the final manuscript.

\section{Ethics approval and consent to participate}

The clinical protocol was approved by the Ethical Committee of the Canton Valais (Switzerland). All participants provided their written informed consent prior to enrolment.

\section{Consent for publication}

Written informed consent was obtained from the patient in Fig. 1 for use of her image for illustration of the institution and media needs. A copy of the written consent is available for review by the Editor-in-Chief of this journal.
Competing interests

The authors DPM, GG and TT were employees of MindMaze SA at the time of the study.

\section{Publisher's Note}

Springer Nature remains neutral with regard to jurisdictional claims in published maps and institutional affiliations.

\section{Author details}

${ }^{1}$ MindMaze SA, Lausanne, Switzerland. 'Laboratory of Cognitive Neuroscience, Brain-Mind Institute, Ecole Polytechnique Fédérale de Lausanne, Lausanne, Switzerland. ${ }^{3}$ Center for Neuroprosthetics, Ecole Polytechnique Fédérale de Lausanne, Lausanne, Switzerland. ${ }^{4}$ Department of Clinical Neurosciences, University Hospital of Lausanne, Lausanne, Switzerland. ${ }^{5}$ Clinique Romande de Réadaptation, Sion, Switzerland. ${ }^{6} \mathrm{Chair}$ in Brain-Machine Interface, Ecole Polytechnique Fédérale de Lausanne, Lausanne, Switzerland.

Received: 21 September 2017 Accepted: 31 October 2017

Published online: 17 November 2017

\section{References}

1. Mozaffarian D, Benjamin EJ, Go AS, Arnett DK, Blaha MJ, Cushman M, Das SR, de Ferranti S, Despres JP, Fullerton HJ, et al. Heart disease and stroke Statistics-2016 update: a report from the American Heart Association. Circulation. 2016;133:e38-e60.

2. Wilkinson PR, Wolfe CD, Warburton FG, Rudd AG, Howard RS, Ross-Russell RW, Beech RR. A long-term follow-up of stroke patients. Stroke. 1997;28: $507-12$.

3. Parker VM, Wade DT, Langton HR. Loss of arm function after stroke: measurement, frequency, and recovery. Int Rehabil Med. 1986;8:69-73.

4. Coupar F, Pollock A, Rowe P, Weir C, Langhorne P. Predictors of upper limb recovery after stroke: a systematic review and meta-analysis. Clin Rehabil. 2012;26:291-313.

5. Winstein CJ, Stein J, Arena R, Bates B, Cherney LR, Cramer SC, Deruyter F, Eng JJ, Fisher B, Harvey RL, et al. Guidelines for adult stroke rehabilitation and recovery: a guideline for healthcare professionals from the American Heart Association/American Stroke Association. Stroke. 2016;47:e98-e169.

6. Kleim JA, Jones TA. Principles of experience-dependent neural plasticity: implications for rehabilitation after brain damage. J Speech Lang Hear Res. 2008;51:S225-39.

7. Schaechter JD. Motor rehabilitation and brain plasticity after hemiparetic stroke. Prog Neurobiol. 2004;73:61-72.

8. Ward N. Treatment of arm and hand dysfunction after CNS damage. In: Oxford Texbook of Neurorehabilitation. Edited by Dietz V, Ward NS. Oxford; 2015. 238-250.[Christopher K (Series Editor).

9. Lang CE, Lohse KR, Birkenmeier RL. Dose and timing in neurorehabilitation: prescribing motor therapy after stroke. Curr Opin Neurol. 2015;28:549-55.

10. Stroke Rehabilitation: Therapy https://www.nice.org.uk/Guidance/CG162. Accessed 6 Nov 2017.

11. Kwakkel G, Kollen B, Lindeman E. Understanding the pattern of functional recovery after stroke: facts and theories. Restor Neurol Neurosci. 2004;22: 281-99.

12. Zeiler SR, Krakauer JW. The interaction between training and plasticity in the poststroke brain. Curr Opin Neurol. 2013;26:609-16.

13. Page SJ, Gater DR, Bach YRP. Reconsidering the motor recovery plateau in stroke rehabilitation. Arch Phys Med Rehabil. 2004;85:1377-81.

14. Demain S, Wiles R, Roberts L, McPherson K. Recovery plateau following stroke: fact or fiction? Disabil Rehabil. 2006;28:815-21.

15. Laver KE, George S, Thomas S, Deutsch JE, Crotty M. Virtual reality for stroke rehabilitation. Cochrane Database Syst Rev. 2015;2:Cd008349.

16. Anguera JA, Boccanfuso J, Rintoul JL, Al-Hashimi O, Faraji F, Janowich J, Kong E, Larraburo Y, Rolle C, Johnston E, Gazzaley A. Video game training enhances cognitive control in older adults. Nature. 2013;501:97-101.

17. Saposnik G, Cohen LG, Mamdani M, Pooyania S, Ploughman M, Cheung D, Shaw J, Hall J, Nord P, Dukelow S, et al. Efficacy and safety of nonimmersive virtual reality exercising in stroke rehabilitation (EVREST): a randomised, multicentre, single-blind, controlled trial. Lancet Neurol. 2016.

18. Sin $\mathrm{H}$, Lee $\mathrm{G}$. Additional virtual reality training using Xbox Kinect in stroke survivors with hemiplegia. Am J Phys Med Rehabil. 2013;92:871-80. 
19. Thieme H, Mehrholz J, Pohl M, Behrens J, Dohle C. Mirror therapy for improving motor function after stroke. Cochrane Database Syst Rev. 2012: Cd008449

20. Franceschini M, Ceravolo MG, Agosti M, Cavallini P, Bonassi S, Dall'Armi $V$, Massucci M, Schifini F, Sale P. Clinical relevance of action observation in upper-limb stroke rehabilitation: a possible role in recovery of functional dexterity. A randomized clinical trial. Neurorehabil Neural Repair. 2012;26:456-62.

21. Garrison KA, Aziz-Zadeh L, Wong SW, Liew SL, Winstein CJ. Modulating the motor system by action observation after stroke. Stroke. 2013:44:2247-53.

22. Holden MK. Virtual environments for motor rehabilitation: review. Cyberpsychol Behav. 2005;8:187-211. discussion 212-189

23. Adamovich SV, Fluet GG, Tunik E, Merians AS. Sensorimotor training in virtual reality: a review. NeuroRehabilitation. 2009;25:29-44.

24. Lohse KR, Hilderman CG, Cheung KL, Tatla S, Van der Loos HF. Virtual reality therapy for adults post-stroke: a systematic review and meta-analysis exploring virtual environments and commercial games in therapy. PLoS One 2014; 9:e93318

25. Brunner I, Skouen JS, Hofstad H, Assmuss J, Becker F, Pallesen H, Thijs L, Verheyden $\mathrm{G}$. Is upper limb virtual reality training more intensive than conventional training for patients in the subacute phase after stroke? An analysis of treatment intensity and content. BMC Neurol. 2016;16:219.

26. Sirtori V, Corbetta D, Moja L, Gatti R. Constraint-induced movement therapy for upper extremities in stroke patients. Cochrane Database Syst Rev. 2009: Cd004433.

27. Fugl-Meyer AR, Jaasko L, Leyman I, Olsson S, Steglind S. The post-stroke hemiplegic patient. 1. A method for evaluation of physical performance. Scand J Rehabil Med. 1975;7:13-31.

28. Page SJ, Fulk GD, Boyne P. Clinically important differences for the upperextremity Fugl-Meyer scale in people with minimal to moderate impairment due to chronic stroke. Phys Ther. 2012;92:791-8.

29. Marx RG, Bombardier C, Wright JG. What do we know about the reliability and validity of physical examination tests used to examine the upper extremity? J Hand Surg Am. 1999:24:185-93.

30. Paternostro-Sluga T, Grim-Stieger M, Posch M, Schuhfried O, Vacariu G, Mittermaier C, Bittner C, Fialka-Moser V. Reliability and validity of the Medical Research Council (MRC) scale and a modified scale for testing muscle strength in patients with radial palsy. J Rehabil Med. 2008:40:665-71.

31. Keith RA, Granger CV, Hamilton BB, Sherwin FS. The functional independence measure: a new tool for rehabilitation. Adv Clin Rehabil. 1987;1:6-18.

32. Hawker GA, Mian S, Kendzerska T, French M. Measures of adult pain: visual analog scale for pain (VAS pain), numeric rating scale for pain (NRS pain), McGill pain questionnaire (MPQ), short-form McGill pain questionnaire (SF-MPQ), chronic pain grade scale (CPGS), short Form-36 bodily pain scale (SF-36 BPS), and measure of intermittent and constant osteoarthritis pain (ICOAP). Arthritis Care Res (Hoboken). 2011;63(Suppl 11):S240-52.

33. R Core Team. R: a language and environment for statistical computing. Vienna, Austria: R foundation for statistical Computing; 2015.

34. Julie P. SPSS survival manual: a step by step guide to data analysis using SPSS for windows version 15: Open University Press; 2007.

35. Krakauer JW, Marshall RS. The proportional recovery rule for stroke revisited. Ann Neurol. 2015;78:845-7

36. Birkenmeier RL, Prager EM, Lang CE. Translating animal doses of taskspecific training to people with chronic stroke in 1-hour therapy sessions: a proof-of-concept study. Neurorehabil Neural Repair. 2010;24:620-35.

37. Lang CE, Macdonald JR, Reisman DS, Boyd L, Jacobson Kimberley T, Schindler-Ivens SM, Hornby TG, Ross SA, Scheets PL. Observation of amounts of movement practice provided during stroke rehabilitation. Arch Phys Med Rehabil. 2009;90:1692-8.

38. Mehrholz J, Pohl M, Platz T, Kugler J, Elsner B. Electromechanical and robotassisted arm training for improving activities of daily living, arm function, and arm muscle strength after stroke. Cochrane Database Syst Rev. 2015: Cd006876.

39. Kimberley TJ, Samargia S, Moore LG, Shakya JK, Lang CE. Comparison of amounts and types of practice during rehabilitation for traumatic brain injury and stroke. J Rehabil Res Dev. 2010;47:851-62.

40. Subramanian SK, Lourenco CB, Chilingaryan G, Sveistrup H, Levin MF. Arm motor recovery using a virtual reality intervention in chronic stroke: randomized control trial. Neurorehabil Neural Repair. 2013:27:13-23.
41. Turolla A, Dam M, Ventura L, Tonin P, Agostini M, Zucconi C, Kiper P, Cagnin A, Piron L. Virtual reality for the rehabilitation of the upper limb motor function after stroke: a prospective controlled trial. J Neuroeng Rehabil. 2013;10:85.

42. Kwakkel G, Lannin NA, Borschmann K, English C, Ali M, Churilov L, Saposnik G, Winstein C, van Wegen EE, Wolf SL, et al. Standardized measurement of sensorimotor recovery in stroke trials: consensus-based core recommendations from the stroke recovery and rehabilitation roundtable. Int J Stroke. 2017:12:451-61.

43. Demers M, Levin MF. Do activity level outcome measures commonly used in neurological practice assess upper-limb movement quality? Neurorehabil Neural Repair. 2017;31:623-37.

44. Shishov N, Melzer I, Bar-Haim S. Parameters and measures in assessment of motor learning in Neurorehabilitation; a systematic review of the literature. Front Hum Neurosci. 2017:11:82.

45. Braun N, Emkes R, Thorne JD, Debener S. Embodied neurofeedback with an anthropomorphic robotic hand. Sci Rep. 2016;6:37696.

46. Llobera J, Gonzalez-Franco M, Perez-Marcos D, Valls-Sole J, Slater M, Sanchez-Vives MV. Virtual reality for assessment of patients suffering chronic pain: a case study. Exp Brain Res. 2013;225:105-17.

47. Martini M, Perez-Marcos D, Sanchez-Vives MV. What color is my arm? Changes in skin color of an embodied virtual arm modulates pain threshold. Front Hum Neurosci. 2013;7:438.

48. Martini M, Perez-Marcos D, Sanchez-Vives MV. Modulation of pain threshold by virtual body ownership. Eur J Pain. 2014;18:1040-8.

49. Riva G. From virtual to real body: virtual reality as embodied technology. J Cyber Ther Rehabil. 2008;1:7-22.

50. Calabro RS, Naro A, Russo M, Leo A, De Luca R, Balletta T, Buda A, La Rosa $G$, Bramanti A, Bramanti P. The role of virtual reality in improving motor performance as revealed by EEG: a randomized clinical trial. J Neuroeng Rehabil. 2017;14:53.

51. Rizzolatti G, Craighero L. The mirror-neuron system. Annu Rev Neurosci. 2004:27:169-92.

52. Padrao G, Gonzalez-Franco M, Sanchez-Vives MV, Slater M, RodriguezFornells A. Violating body movement semantics: neural signatures of selfgenerated and external-generated errors. Neurolmage. 2016;124:147-56.

53. Garipelli G, Liakoni V, D. P-M, Duc C, Gilart de Keranflec'h C, Kinzner H, Johr J, Tadi T, Michel P, Diserens K. Virtual Reality based Neuroreabilitation in Acute Stroke: A feasibility study.submitted.

54. Kinzner H, Garipelli G, Perez-Marcos D, Tadi T, Diserens K. Virtual reality based upper limb Neurorehabilitation in acute stroke: A single-case study. In 45th annual meeting of the Society for Neuroscience; Oct 17-21; Chicago,USA. 2015.

55. Rizzo A, Kim GJ. A SWOT Analysis of the field of virtual reality rehabilitation and therapy. Presence: Teleoperators \& Virtual. Environments. 2005;13:119-46.

\section{Submit your next manuscript to BioMed Central and we will help you at every step:}

- We accept pre-submission inquiries

- Our selector tool helps you to find the most relevant journal

- We provide round the clock customer support

- Convenient online submission

- Thorough peer review

- Inclusion in PubMed and all major indexing services

- Maximum visibility for your research

Submit your manuscript at www.biomedcentral.com/submit 